\title{
The choice of methods for modeling organizational and technological solutions in the construction of buildings and structures
}

\author{
Anastasia Abramova* \\ Moscow State University of Civil Engineering, 129337, Moscow, Russia
}

\begin{abstract}
An important task in the construction of buildings and structures is the choice of the most rational solutions in terms of organization and technology of construction production.

Currently, the complexity and variety of organizational and technological decisions in the dynamics of the process of erecting buildings and structures for various purposes requires research.

To this end, it is necessary to improve existing or develop new organizational and technological solutions, in conditions when the tasks are set to increase the growth in the volume of housing construction.

The author is faced with the task of forming an integrated system that includes organizational and technological solutions, methods and assessment of the effectiveness of the study.

It is assumed that the results of the study will be in demand by construction organizations to maintain competitiveness, paying attention to organizational and technological solutions, both at the stage of preparation and during construction. This will prevent losses, increase the effective functioning of construction organizations in the market, and strengthen their business reputation.

Scientific novelty lies in the formation of parameters and their classification, methods of modeling organizational and technological solutions.

To assess organizational and technological solutions, it is necessary to study methods and ways of measuring them.

In the course of the research, an analysis of the methods widely used at present for the qualitative and quantitative assessment of organizational and technological solutions was carried out. Qualitative assessment methods make it possible to reveal the significance of certain factors of a phenomenon through the analysis of competent opinions. In the case of studying the influence of organizational and technological solutions on construction processes, there are no measurable physical parameters, objects inaccessible to perception and large volumes of statistical data.

The article concludes that empirical, theoretical and quantitative methods are difficult for the research chosen by the author. Therefore, the author of this article chose the Monte Carlo method (MCM) as a research
\end{abstract}

*Corresponding author: shatrovaan@mail.ru 
method - a group of numerical methods for studying random processes.

Also, the work identified a vector for further research.

\section{Introduction}

The construction industry signals not only a vibrant economy, but also the standard of living of the population.

Since it is possible to purchase housing only when individual financial well-being is at least at an average level, it is precisely by construction and purchasing power that one can focus on the well-being of the population.

To analyze the current situation in the construction industry, as well as to determine the number of construction organizations that exist in the country today, consider the statistics of Rosstat.

The graph makes it clear that the number of commissioned square meters of housing is growing slightly. It is affected not only by the increase in bankruptcies and closings of construction companies, but also by the uncertainty in demand, the lack of necessary investments for construction. Hence the refusal to implement a number of projects, the mothballing of the construction of some objects.

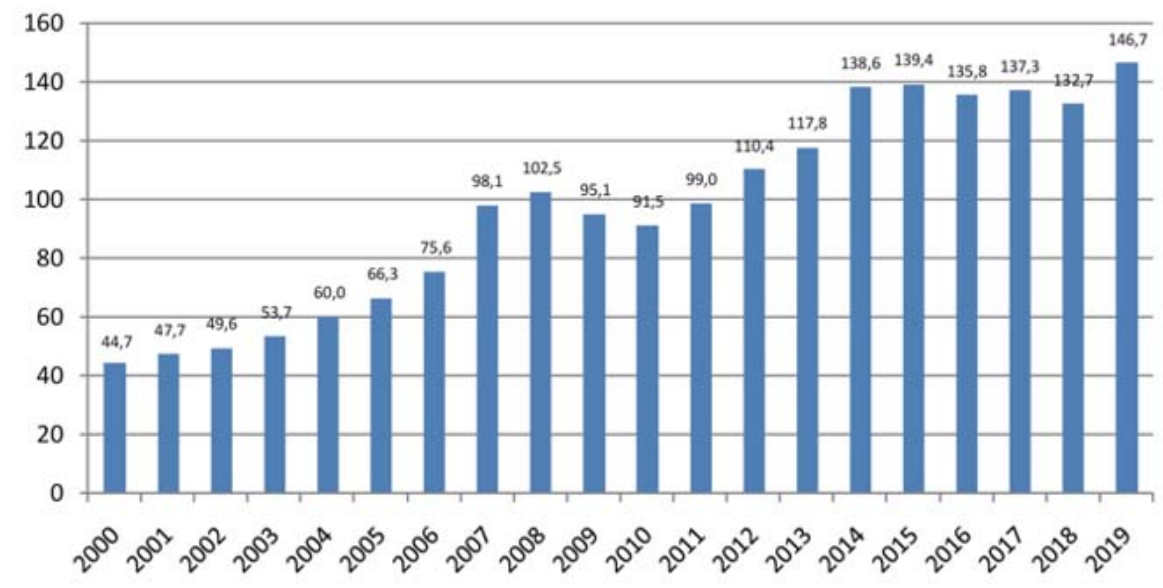

Fig. 1. The number of $\mathrm{m}^{2}$ put into operation (data from the Federal Statistics Service)

Organizational and technological solutions (OTP) are understood as a set of measures (organizational, technical, technological) aimed at achieving the final result - putting the facility into operation in accordance with the established deadlines and required quality [1].

The main organizational and technological solutions are developed before the start of the design of construction production (see tab. 1). For this, it is necessary to obtain complex information of a technical and other nature about the future construction object.

In connection with the difficult situation observed in the construction industry of the country, it can be concluded that in most cases the developed solutions and complexes of measures that can be guided by were not effective enough.

Table 1. Selection of organizational and technological solutions for construction production

\begin{tabular}{|c|c|c|}
\hline & $\begin{array}{l}\text { Selection of possible } \\
\text { technological } \\
\text { organizational methods for }\end{array}$ & $\begin{array}{l}\text { Final choice } \quad \text { of } \\
\text { solution based on } \\
\text { variant comparison }\end{array}$ \\
\hline
\end{tabular}




\begin{tabular}{|l|l|l|}
\hline & $\begin{array}{l}\text { the construction of buildings } \\
\text { and structures }\end{array}$ & \\
\hline $\begin{array}{l}\text { 1.Engineering and } \\
\text { geological surveys }\end{array}$ & 1. Established methods & $\begin{array}{l}\text { 1. Feasibility study of } \\
\text { the selected options }\end{array}$ \\
\hline 2.Climatic surveys & $\begin{array}{l}\text { 2. Progressive methods of } \\
\text { construction of buildings and } \\
\text { structures }\end{array}$ & $\begin{array}{l}\text { Comparison of } \\
\text { technical and economic } \\
\text { indicators for the } \\
\text { proposed options }\end{array}$ \\
\hline $\begin{array}{l}\text { 3.Production research } \\
\text { 4. Architectural and } \\
\text { construction solutions }\end{array}$ & $\begin{array}{l}\text { introducing new construction } \\
\text { methods }\end{array}$ & \\
\hline
\end{tabular}

For systematization, these difficulties can be divided into groups, such as:

- economic - expressed in financial stability, ensuring the performance of construction and installation works (CMP) and excluding the risk of construction in progress;

- labor - related to experience, competencies, qualifications of workers and engineering and technical workers (ITR)

- production - implying the degree of mechanical equipment and the level of application of innovative materials and modern technologies for performing construction and installation work (BIM-technologies, laser scanning, nano-concrete, fiber-reinforced concrete, software and computational complexes, etc.).

The decisions taken should contribute to improving the efficiency, quality and manufacturability of finished construction products, and the most rational use of the possibilities of production factors.

Despite the existence of certain stages in the choice of the options under consideration, difficulties arise with the adoption of rational organizational and technological decisions for the construction of buildings and structures. This is due, first of all, to the limited amount of variance and a low-objective approach to comparing the options used [2-4].

Table 2. Formation of parameters of compensatory measures affecting the TEP of the investment and construction project

\begin{tabular}{|c|c|}
\hline $\begin{array}{l}\text { Coded values } \\
\text { parameter }\end{array}$ & Parameter name \\
\hline $\mathrm{X} 1$ & $\begin{array}{l}\text { Minimization or achievement of a given construction period for an } \\
\text { object. }\end{array}$ \\
\hline $\mathrm{X} 2$ & Minimizing the cost of building an object. \\
\hline X 3 & $\begin{array}{c}\text { Achieving a given level of quality of construction and installation } \\
\text { work and the object as a whole. }\end{array}$ \\
\hline $\mathrm{X} 4$ & $\begin{array}{c}\text { Determination of sources of supply of resources and assessment of } \\
\text { partners and competitors. }\end{array}$ \\
\hline $\mathrm{X} 5$ & $\begin{array}{l}\text { Modern laboratory equipment for quality control during the } \\
\text { construction of the facility and during its commissioning. }\end{array}$ \\
\hline X 6 & $\begin{array}{c}\text { Formation of production units (brigades) (highly qualified workers } \\
\text { with certain experience and work experience). }\end{array}$ \\
\hline
\end{tabular}




\begin{tabular}{|c|c|}
\hline X 7 & $\begin{array}{c}\text { The choice of modern technologies (materials, equipment and } \\
\text { methods of performing work). }\end{array}$ \\
\hline X 8 & Determination of resource requirements. \\
\hline X 9 & Availability and quality of project documentation (PPD). \\
\hline X10 & Qualification of workers and engineers. \\
\hline
\end{tabular}

Development of a system that includes organizational and technological solutions, methods and assessment of the effectiveness of the research carried out in the implementation of projects for the construction of residential buildings, which, according to the preliminary forecast, will allow:

- to increase funding for housing construction by $1-5 \%$;

- to increase the growth of housing commissioned in accordance with the established terms and quality by $10-15 \%$;

- to increase the number of employees who are involved in the implementation of construction projects by $3-8 \%$;

- to reduce the prime cost per square meter of housing stock by $5-10 \%$;

- increase the efficiency of production and labor through the introduction of new technologies by $5-10 \%$.

\section{Materials and methods}

To assess organizational and technological solutions, it is necessary to study methods and ways of measuring them. In the course of the research, the following methods were analyzed that are most appropriate in the case of assessing OTP [5-6]:

1. Optimization methods seem to be promising, in particular, optimization methods for large-scale problems, which are successfully applied when all the necessary information is available. The main problem of using multicriteria optimization methods, in particular, methods for constructing Pareto sets or concession methods, when solving problems that can formalize a limited number of parameters, is also the problem of mutual correlation of various criteria.

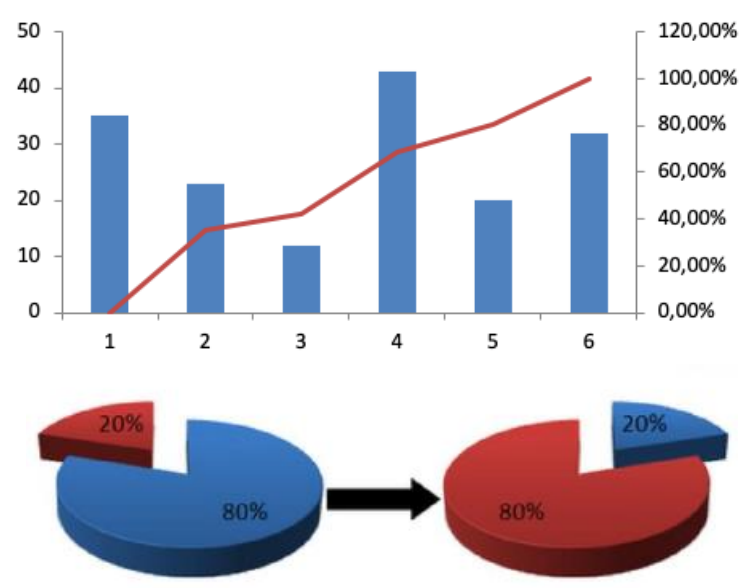

Fig. 2. Construction of Pareto sets 
2. The ranking of criteria by significance can be achieved by expert methods, for example, the Delphi method. The results obtained in the process of interviewing experts are subject to mathematical analysis, during which the correctness of the collected data will be established by determining the degree of agreement of experts' opinions [7].

3. Simulation techniques work well with complex systems when all the required information is available. If the initial data is incomplete and unclear, the resulting errors can significantly distort the simulation results.

4. Specific activities with a certain set of rules and tools used can be modeled using game theory methods. However, there is a number of problems associated with the laboriousness of collecting and processing information, as well as the fundamental possibility of reflecting by this method the entire depth and diversity of processes.

5. Expert systems or artificial intelligence methods are successfully applied in a relatively stable environment or when working with dynamically changing, but standardized situations.

6. When modeling the behavior of the external environment of an enterprise, methods of constructing dynamic macromodels can be recommended.

7. In the theory of experiment planning, the area of vector space is represented by a set of factors that are random in nature and significantly affect the object under study. The object of research in this case is the construction industry, considered in the form of a cybernetic system «black box» [8].

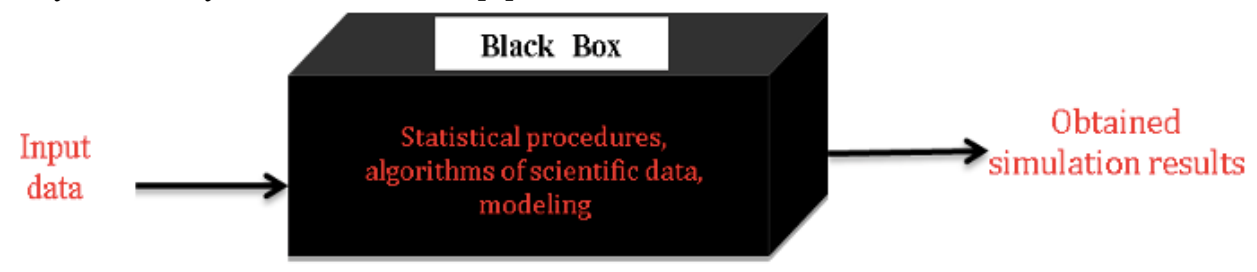

Fig. 3. Theory of experiment planning

8. To consider and define trust, the theory of evidence of Dempster-Schafer usually combines different functions of trust, calculating the sum of their base probabilities according to Dempster's rule [9].

If current evidence leads to multiple trusts about the same hypotheses, then the trusts must be combined to obtain overall confidence in the hypotheses.

Having evidence, we set the set, defined on the discrimination frame, basic probabilities $\mathrm{m}_{1}$, that is this

$$
\left\{m_{1}\left(M_{i}\right), \forall M_{i} \in \Theta\right\} \rightarrow \mathrm{Bel}_{1}
$$

allows us to determine the credibility of certain hypotheses.

Thus, the author considered methods for assessing OTR, which are quite effective tools.

9. Monte Carlo Methods (MCM) - a group of numerical methods for studying random processes. The essence of the Monte Carlo method is as follows: the process is modeled using a generator of random variables. This is repeated many times, and then, based on the received random data, the probabilistic characteristics of the problem being solved are calculated. 


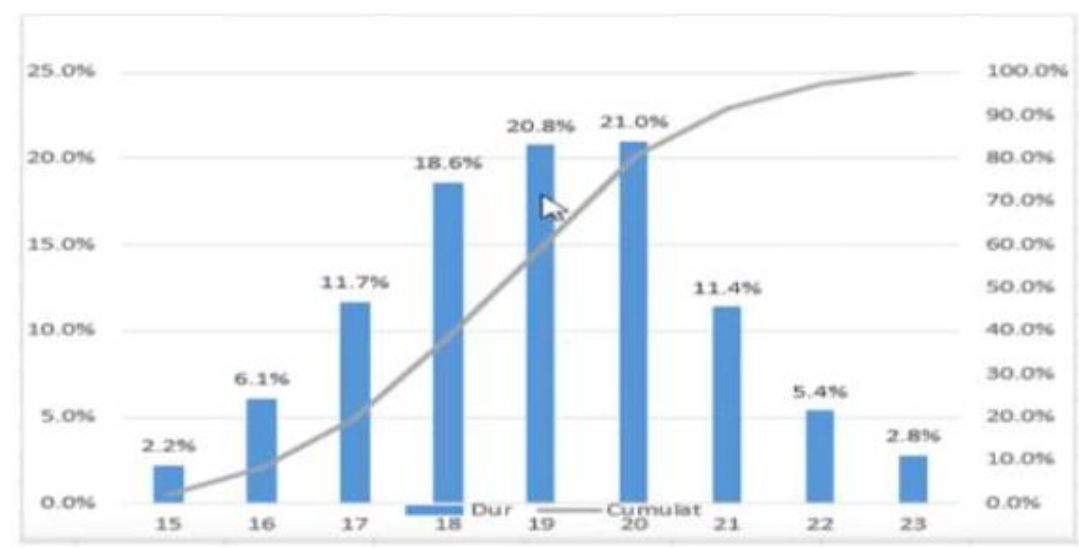

Fig. 4. Application of the Monte Carlo method in scheduling construction work

The Monet-Carlo method consists of the following steps:

1. Computer simulation of pseudo-random sequences with a given correlation and the law of probability distribution (Monte Carlo method), simulating random values of parameters on a computer at each test;

2. Using the obtained numerical sequences in mathematical simulation models.

3. Statistical processing of simulation results.

\section{Results of the study}

Thus, the Monte Carlo Methods (MMK) considered by the author are quite effective tools and allow you to reveal the value of certain factors of a phenomenon through the analysis of competent opinions, given the absence of measurable physical parameters, objects inaccessible to perception and large volumes of statistical data [10].

1. The Monte Carlo method has a high degree of parallelism when it is implemented both on MPI and on Open MP, programs based on it allow uniformly load the computing nodes of cluster systems.

2. The disadvantages are: a) The margin of error is not precisely defined but includes some randomness. This, however, is more psychological than real difficulty. b) The static error decreases slowly. c) The need to have random numbers.

3. With the help of these methods, the hypothesis will be confirmed, and it is also planned to check the conducted theoretical study, with the subsequent implementation of its results.

\section{Conclusion}

Thus, an analysis was carried out of various methods for modeling organizational and technological solutions, which are widely used at present, to study their impact on construction processes. The studies provide for a whole range of measures aimed at improving the quality of production activities and technical and economic indicators in the construction of buildings and structures.

In further studies, the approach outlined in the article can be used in the methodology for the formation of an integrated system, including organizational and technological solutions, methods and assessment of the effectiveness of the study. 


\section{References}

1. A.A. Lapidus, I.L. Abramov, Stability of organizational and production systems in conditions of risks and uncertainty of construction production, Prospects for science, 6 (105), 8-11 (2018).

2. B. Zhadanovsky, S. Sinenko, The methodic of calculation for the need of basic construction machines on construction site when developing organizational and technological documentation, E3S Web of Conferences Ser. "High-Rise Construction 2017, HRC 2017”, 03077 (2018).

3. P. Oleinik, T. Kuzmina, Modeling the reduction of project making duration, MATEC Web of Conferences, 00129 (2017).

4. R. Kazaryan, D. Pogodin, A.Shatrova, Aspects of scheduling processes and results of the reorganization of projects in high-rise construction objects, E3S Web of Conferences, 97, 04002 (2019). https://doi.org/10.1051/e3sconf/20199704002.

5. A.A. Gusakov, Organizational and technological reliability of construction production (in conditions of automated design systems) (Stroyizdat, 1974).

6. V.O. Chulkov, Infographics as a tool for modeling the individual's thinking activity, in the collection: Innovations in the sectors of the national economy, as a factor in solving the socio-economic problems of our time, a collection of reports and materials of the VI International Scientific and Practical Conference, ANO VO "Institute of Continuing Education", pp. 17-29 (2016).

7. P.P. Oleinik, A.I. Shatrova, Innovative methods of organizing construction, Technology and organization of construction production, 1, 18-20 (2016).

8. A.I. Abramova, On the issue of choosing compensatory measures in the implementation of investment construction projects, Science and business: ways of development, 3 (105), 102-106 (2020).

9. A.I. Shatrova, E.A. Rukosueva, Organizational and technological solutions for effective planning of construction production in modern conditions, In the collection: Days of student science Collection of reports of a scientific and technical conference on the results of research work of students of the Institute of Construction and Architecture, pp. 1311-1313 (2019).

10. Yu. A. Makarichev, Yu.N. Ivannikov, Experiment Design and Data Processing Techniques: A Tutorial (FGBOU VO "SamSTU", Moscow, 2016). 